\title{
Contact-free Stress Monitoring for User's Divided Attention
}

\author{
Dvijesh Shastri, Avinash Wesley, Ioannis Pavlidis \\ Computational Physiology Lab, Department of Computer Science, University of Houston,
} USA

\section{Introduction}

During many occasions, computer users and machine users in general have to perform more than one task simultaneously. When a combination of events demands critical decisions and rapid actions, the subject's alertness is raised. If alertness persists, it is likely to reach beyond certain acceptable levels and ultimately transform into stress. Stress due to the subject's divided attention may lead to degradation of his/her performance for one or more simultaneous tasks.

In this study, we describe research that aims to quantify stress levels of subjects due to divided attention. Such cases often arise in software use and beyond and take a serious toll on performance and emotion. The proposed method is based on the thermal signature of the face. We use the supraorbital skin temperature as the physiological variable of interest. Because of higher measurement sensitivity and its contact-free nature, facial thermal stress monitoring has been an increasingly popular approach (Puri et al., 2005, a. Pavlidis et al., 2002, b. Pavlidis et al., 2002). Contact sensor based physiological measurement methods restrict subjects' motion and increase their awareness of being monitored (Yamaguchi et al. 2006, Yamakoshi et al. 2007, Healey et al 2005). Therefore, it is not a very effective way for continuous physiological monitoring.

Although concurrent execution of multiple tasks is part of human life, no sufficient research has been done to understand its effects on human emotional states and performance. The purpose of this study is to evaluate a subject's emotional states and effect on performance while executing parallel tasks. We use simulated driving and concomitant cell phone conversation in our experimental design. This is a quintessential divided attention example in man-machine interaction with which most people are familiar with.

The results of our research show that the simultaneous performance of dual tasks increases blood flow in the supraorbital vessels and frontalis muscle. A change in blood flow alters heat dissipation from the supraorbital region and thus, it can be monitored through a thermal camera. This work opens a new area of research in non-contact stress monitoring for divided attention situations. 


\section{Methodology}

During concurrent dual tasks performance, we have observed considerable skin temperature increase in the supraorbital region of all 11 subjects. This elevated temperature is the results of increased blood flow to the supraorbital region in order to supply energy for the increased mental activities. This finding matches our previous reporting that user stress is correlated with the increased blood flow in the frontal vessel of the supraorbital region (Puri et al., 2005). In the past, we used the periorbital region to quantify stress during startle response and polygraph examination (a. Pavlidis et al., 2002, b. Pavlidis et al., 2002, Tsiamyrtzis et al. 2006). As oppose to our requirement, that is to monitor sustained stress during the divided attention situations, the periorbital region is used to quantify instantaneous stress. Moreover, the users' continuous moving eyes during simulated driving prevent us from using the periorbital measurement in this study. As a result, we focus our attention to the skin temperature of the supraorbital region and its involvement in determining sustained stress.

Unlike the periorbital area, which accommodates a wide range of temperature values, the supraorbital area is plateau in nature. When tracks this plateau region, thin ranged feature points of the tracker compromise its stability to a certain degree (Dowdall et. al 2007). As a consequence, the tracker is shifted from its target position repeatedly. Therefore, we select a larger region of interest for the tracking algorithm but compute the mean thermal footprint of an appropriate subset of the region (Pogreška! Izvor reference nije pronađen.).

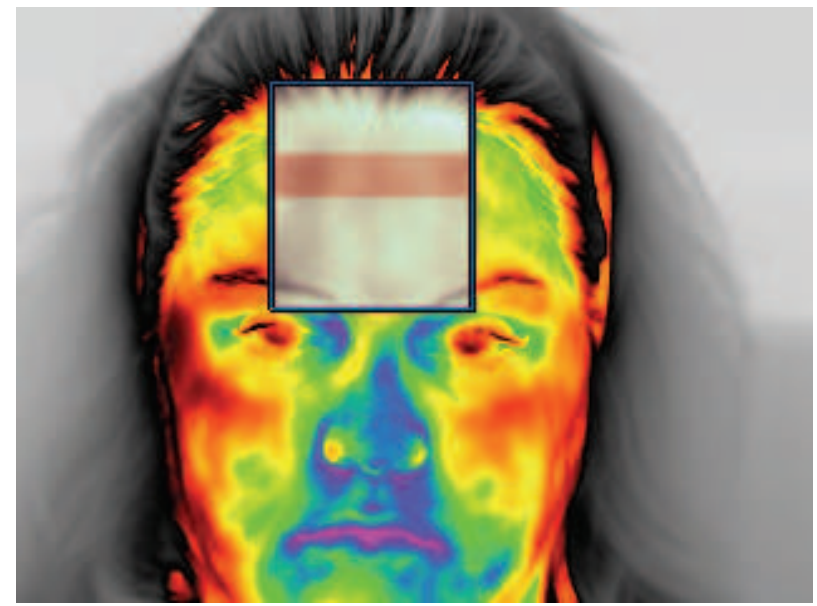

Fig. 1. The supraorbital signal was extracted from the mean thermal footprint of the pink colored region inside the rectangle.

For every subject, we select a Region of Interest (ROI) that covers the supraorbital area (see Figure 1). We compute the mean temperature of the ROI for every frame in the thermal clip. We, thus, produce a $1 \mathrm{D}$ supraorbital temperature signal from the $2 \mathrm{D}$ thermal data. However, due to imperfections in the tissue tracking and systemic noise, the measurement from this area carries substantial noise, which we suppress to a large degree by a Fast Fourier 
Transformation (FFT) based noise cleaning approach (Tsiamyrtzis et al. 2006). Finally, we model the global trend of the noise-cleaned signal by fitting a linear polynomial to each experimental segment. Figure 2 illustrates the raw temperature signal, the noise cleaned signal, and the linear segment fitting. The slope value describes the temperature evolution of each segment.

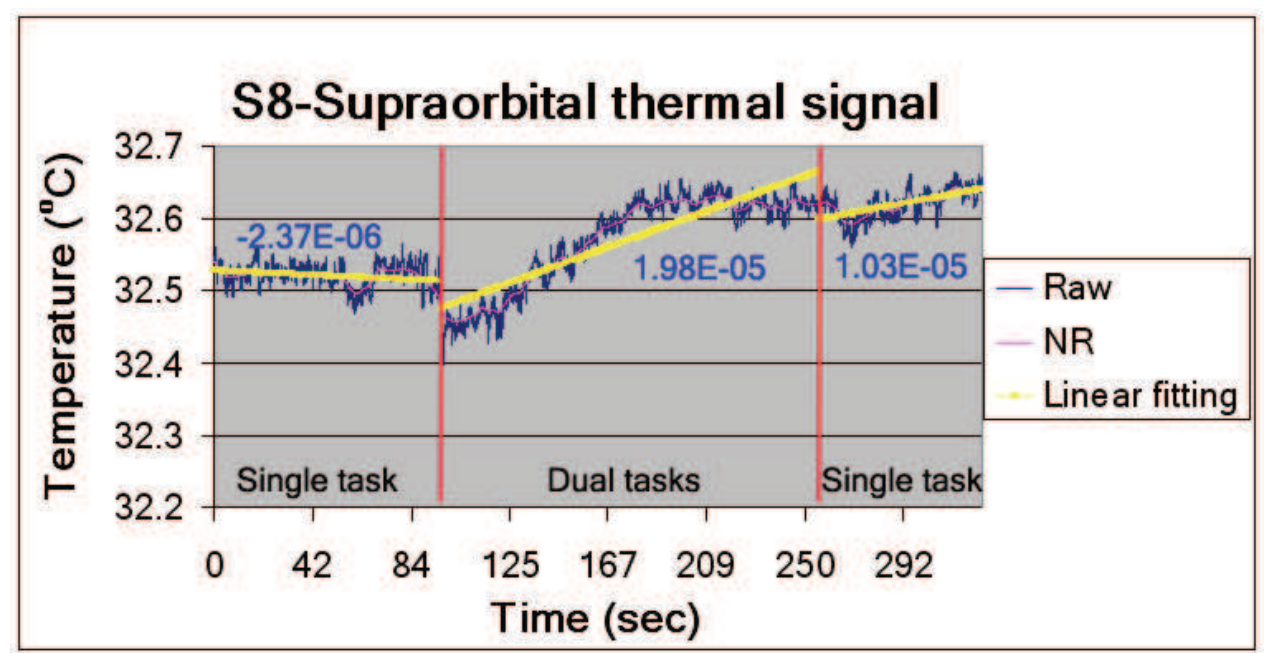

Fig. 2. The supraorbital raw temperature signal (marked in blue color), noise reduced (NR) temperature signal (marked in pink color) and linear fitting (marked in yellow color). Slope values of the respective segments are showed in blue colored text.

\section{Experimental Design}

We used a high quality Thermal Imaging (TI) system for the data collection. The centerpiece of the TI system is a ThermoVision SC6000 Mid-Wave Infrared (MWIR) camera (FLIR Systems) $\left(\mathrm{NEDT}=\$ 0.025^{\circ} \mathrm{C}\right)$. For each subject, we recorded 3 thermal clips: while the subject resting, playing the driving simulation game, and the cooling off period. Thus, we collected 11 subjects $\times 3$ clips $/$ subject $=33$ thermal clips.

The data set features subjects of both genders, different races, and with varying physical characteristics. The subjects were placed 6 feet away from the thermal camera (Fig. 3). We used a XBOX-360 game console and the Test Drive: Unlimited game to simulate real life driving. The subjects were asked to follow all traffic signs, drive normally and not to race during the experiment. They were given an opportunity to test drive before the experiment begun to facilitate themselves with the simulated driving setup. After the test drive, the subjects were asked to relax for 5 minutes before the experiments begun. This helps to isolate effects of other stress factors that the subjects may have carried from the past events. The subjects' facial thermal signature was recorded during this relaxation period. We called it baseline segment. 
Next, the subjects were asked to play the driving simulation game. This part of the experiment lasted for approximately 5 minutes. After around a minute of the simulated driving (the initial single task segment), we made a cell phone call to the subjects and played a set of prerecorded questions in the following order:

Instruction: Please do not hang up until you are told so.

Q1: Are the lights $\mathrm{ON}$ in the room, yes or no?

Q2: Are you a male or female?

Q3: Who won the American civil war, the north or the south?

Q4: What is $11+21$ ?

Q5: How many letter ' $\mathrm{e}$ ' are in the word experiment?

Q6: I am the son of a mom whose mother in law's son hit. How am I related to the other son? Q7: My grandma's son hit his son. How are the sons related?

Q8: A man is injured in 1958 and died in 1956. How is that possible?

Q9: What is $27+14$ ?

Instruction: You may now hang up the phone and pay attention to the game.

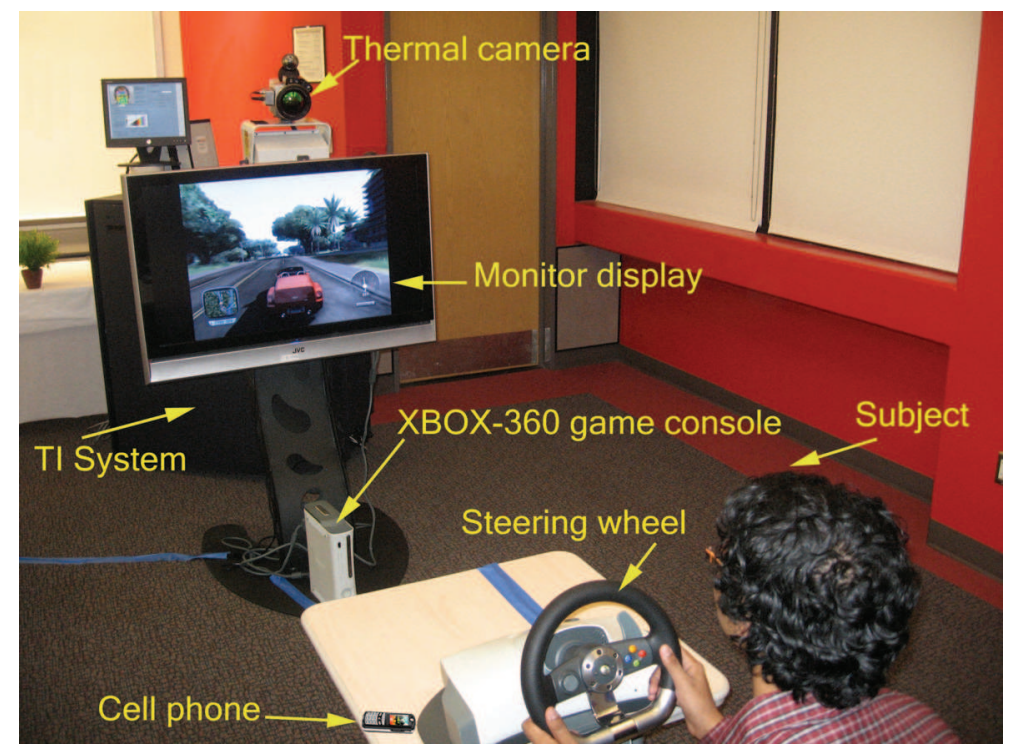

Fig. 3. Experimental setup; subject, imaging equipment, xBOX-360.

The question set was a combination of basic, logical, simple math and ambiguous questions. The order of the questions was designed to build-up emotional pressure on the subjects. Additional pressure was achieved by repeating one more time every question that was incorrectly answered. The subjects were supposed to drive while talking on the cell phone (the dual task segment). At the end of the phone conversation, subjects put the phone down and continued driving till the end of the experiment (the latter single task segment). 
Finally, the subjects relaxed for 5 minutes. The purpose of this so-called cool-off segment was to monitor physiological changes after the simulated driving experiment.

\section{Experimental Results}

We used the slope as the thermal stress indicator. For each subject, we compute the slope value for every experimental segment as described in the Methodology section. Fig. 4 shows the mean slope values of the various segments for the entire data set (mean subject). The graph clearly indicates that the temperature increase during the concurrent dual tasks is the highest among all segments. Since the temperature increase is correlated to blood flow, the results indicate that more blood flows to the supraorbital region during the dual task action. With the exception of subject-6 (S6), the dual task segment of all subjects has a higher temperature gradient than its corresponding baseline and initial single task. This validates our assumption that the user's divided attention while critical tasks performance increases the user's stress level.

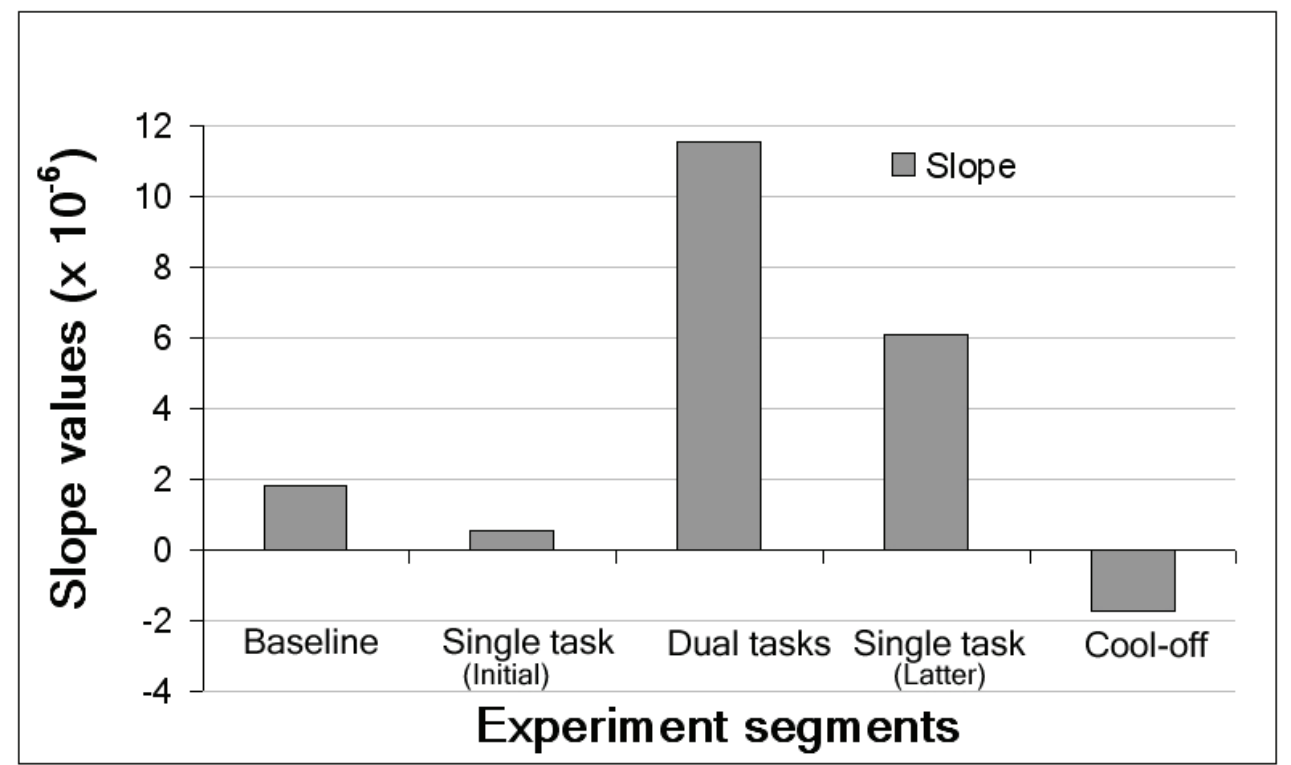

Fig. 4. Mean slope value of the experimental segments. The temperature increase is the highest during the dual tasks performance.

While performing the single task second time (Latter), most of the subjects carried the mental stress from the past dual tasks period. On the other hand, as the ablove graph illustrates, the subjects experienced less mental stress for the same single task performed first time (initial) as it was conducted right after the relaxation period (baseline) where they got an opportunity to isolate their mental stress due to the past events. Most of the subjects admitted during the post-debriefing session that they were thinking about their dual tasks 
performance while performing the latter single task. Therefore, the subjects experienced higher mental stress during the latter single task as compared to the initial single task. Figure 4 confirms this finding, mathematically. It illustrates that the rate of temperature change of the latter single task is higher than that of the initial single task.

The rationale behind higher slope value of the baseline segment as compare to the initial single task segment is that many subjects played the driving simulation game first time ever during the test drive. Thus, the baseline segment reflects the stress level they acquired during the test drive period, which was right before the baseline segment. The test drive helped isolating anxiety of performing a task that was never performed before. Therefore, the initial single task represents stress due to conducting the single challenging task only, i.e. driving the simulated car.

S6 is an interesting subject. The supraorbital temperature of the subject increased almost half of the dual task period and then decreased during the remaining period (Figure 5). We found the temperature decrease on the supraorbital was due to emotional perspiration. The cause for the emotional perspiration during divided attention is unknown to us at this point of our research. More experiments are required to reveal the full picture and currently we are pursuing it.

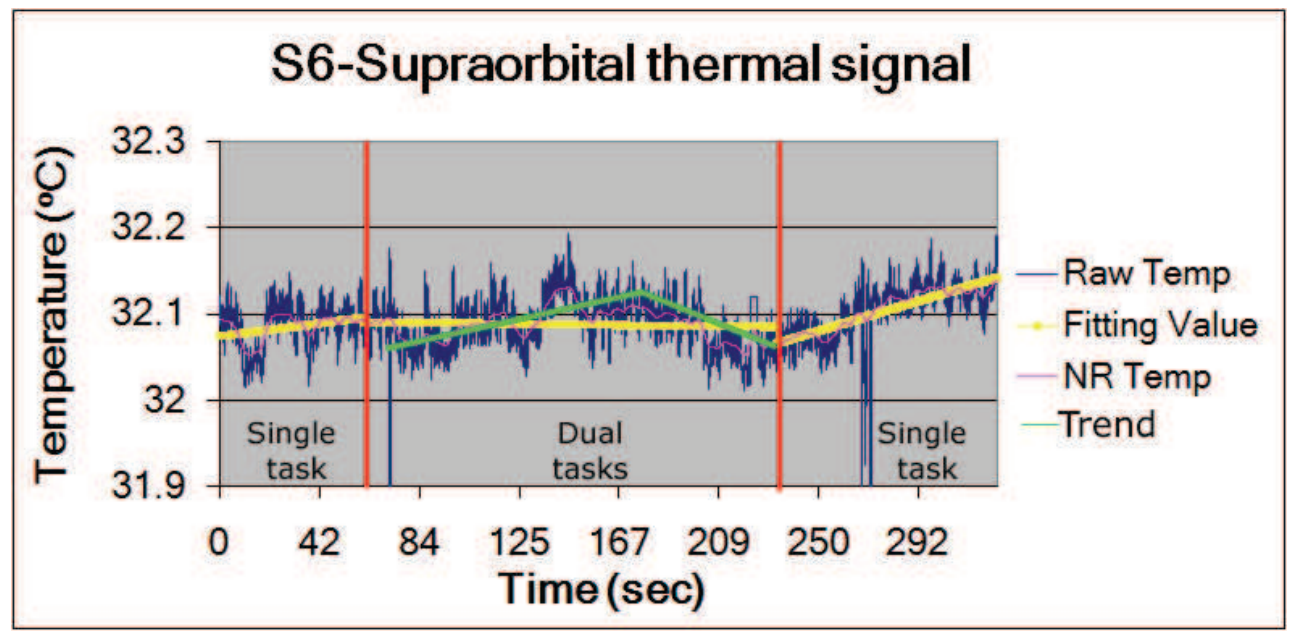

Fig. 5. During the dual task period, the supraorbital temperature (marked in blue color) of S6 shows ascending global trend in the first half and then descending global trend in the second half of the period as marked in green color. Therefore, the linear fitting to the segment is approximately a horizontal line.

In all cases, the rate of temperature change of the cool-off segment is much slower than that of the dual task segment. In most cases, the rate of the temperature change of the cool-off segment is slower than that of the initial single task, and the latter single segments. This illustrates that the subjects indeed felt relaxed after 5 minutes of intense mental activity. 
Performance of the drivers degraded during the dual task segment, as measured by the point system of the simulator. This was inversely proportional to the average stress level measured through the supraorbital channel.

\section{Conclusion}

This research work demonstrates the feasibility of stress quantification in situations where the attention of the user is divided. Psychologically kosher (i.e., unobtrusive) quantification of stress and its correlation to user performance and emotion are of singular importance in man-machine interaction. We have also proved that talking on a cell phone during simulated driving increases the supraorbital skin temperature significantly. This finding clearly demonstrates that concurrent performance of two critical tasks increases user's stress level. Thus, we can safely claim that the proposed system is capable of reflecting the user's stress in divided attention situations. A feedback system can be devlope that alerts the users about their mental status based on the facial thermal signature. The initial experiment with a small dataset shows a lot of promise. More multi-faceted and extensive experiments, however, are necessary to understand the complete picture.

The proposed system can be use to monitor physiological behavior during critical multitasking activities. The potential use of our system is to understand the vehicle drivers' emotional states in order to reduce traffic accidents. The major bottelnack of this system is very high cost of the thermal camera, which prevents the system to be a practial applciation. We hope the cost of the thermal camera will reduce in the near future.

\section{Acknowledgments}

This material is based upon work supported by the National Science Foundation under Grant No. 0414754, entitled "Interacting with Human Physiology."

\section{References}

Dowdall, J., Pavlidis, I., and Tsiamyrtzis, P. (2007) . Coalitional tracking. Computer Vision and Image Understanding 106, 2-3, (2007), 205-219, ISSN: 1077-3142

FLIR Systems, 70 Castilian Dr., Goleta, California 93117, http:/ / www.flir.com

Healey, J.A., and Picard, R.W. (2005). Detecting stress during real-world driving tasks using physiological sensors. IEEE Transactions on Intelligent Transportation Systems 6, 2 (6 2005), 156-166. ISSN: 1524-9050

a. Pavlidis, I., Eberhardt, N.L., and Levine, J. (2002). Human behavior: Seeing through the face of deception. Nature 415, 6867 (01 2002), 35.

b. Pavlidis, I., and Levine, J. (2002) Thermal image analysis for polygraph testing. IEEE Engineering in Medicine and Biology Magazine 21, 6 (11-12, 2002), 56-64, ISSN: 07395175

Puri, C., Olson, L., Pavlidis, I., Levine, J., and Starren, J. (2005). StressCam: non-contact measurement of users' emotional states through thermal imaging. $\mathrm{CHI}^{\prime} 05$ extended 
abstracts on Human factors in computing systems, pp. 1725-1728, ISBN: 1-59593-002-7 ACM press, Portland, OR, USA

Tsiamyrtzis, P., Dowdall, J., Shastri, D., Pavlidis, I., Frank, M., and Ekman, P. (2006). Imaging facial physiology for the detection of deceit. International Journal of Computer Vision 71, 2, (10, 2006), 197-214, ISSN: 0920-5691 (Print) 1573-1405 (Online)

Yamaguchi, M., Wakasugi, J., and Sakakima, J. (2006). Evaluation of Driver Stress using Biomarker in Motor-vehicle Driving Simulator. 28th Annual International Conference of the IEEE Engineering in Medicine and Biology Society, pp. 1834-1837, ISBN 142440033-3, 30 Aug - 3 Sep. 2006, New York City, USA

Yamakoshi, T., Yamakoshi , K., Tanaka, S., Nogawa , M., Shibata , M., Sawada , Y., Rolfe , P., and Hirose , Y. (2007) A Preliminary Study on Driver's Stress Index Using a New Method Based on Differential Skin Temperature Measurement. 29th Annual International Conference of the IEEE Engineering in Medicine and Biology Society, pp. 722 - 725, ISBN: 978-1-4244-0787-3, 22-26 Aug. 2007, France 




\section{Human Computer Interaction \\ Edited by loannis Pavlidis}

ISBN 978-953-7619-19-0

Hard cover, 522 pages

Publisher InTech

Published online 01, October, 2008

Published in print edition October, 2008

This book includes 23 chapters introducing basic research, advanced developments and applications. The book covers topics such us modeling and practical realization of robotic control for different applications, researching of the problems of stability and robustness, automation in algorithm and program developments with application in speech signal processing and linguistic research, system's applied control, computations, and control theory application in mechanics and electronics.

\section{How to reference}

In order to correctly reference this scholarly work, feel free to copy and paste the following:

Dvijesh Shastri, Avinash Wesley and loannis Pavlidis (2008). Contact-free Stress Monitoring for User's Divided Attention, Human Computer Interaction, Ioannis Pavlidis (Ed.), ISBN: 978-953-7619-19-0, InTech, Available from: http://www.intechopen.com/books/human_computer_interaction/contact-

free_stress_monitoring_for_user_s_divided_attention

\section{INTECH}

open science | open minds

\section{InTech Europe}

University Campus STeP Ri

Slavka Krautzeka 83/A

51000 Rijeka, Croatia

Phone: +385 (51) 770447

Fax: +385 (51) 686166

www.intechopen.com

\section{InTech China}

Unit 405, Office Block, Hotel Equatorial Shanghai

No.65, Yan An Road (West), Shanghai, 200040, China

中国上海市延安西路65号上海国际贵都大饭店办公楼 405 单元

Phone: +86-21-62489820

Fax: $+86-21-62489821$ 
(C) 2008 The Author(s). Licensee IntechOpen. This chapter is distributed under the terms of the Creative Commons Attribution-NonCommercialShareAlike-3.0 License, which permits use, distribution and reproduction for non-commercial purposes, provided the original is properly cited and derivative works building on this content are distributed under the same license. 